\title{
Imaging vulnerability: the iconography of climate change
}

\author{
Kate Manzo \\ Department of Geography, University of Newcastle, Newcastle upon Tyne NE1 7RU \\ Email: kate.manzo@ncl.ac.uk
}

Revised manuscript received 30 January 2009

\begin{abstract}
This paper explores the iconography of climate change in contemporary climate action campaigns in the UK. I aim to show how sample images are simultaneously scientific denotations of global warming and cultural connotations of danger and vulnerability. I further demonstrate that while similar images are associated with different agendas and geographical visions, they attach to a shared discourse of vulnerability that has Western (colonial) roots. The paper concludes with an overview of possible ways for climate action campaigns to effectively convey their political messages without recycling colonial visions of the world.
\end{abstract}

Key words: climate change, development, vulnerability, danger, colonialism

\section{Introduction}

This paper contributes to a growing body of literature on the visual communication of climate change issues and messages (Brönnimann 2002; Doyle 2007; Hulme 2004; Jasanoff 2007; Nicholson-Cole 2005). It does so by considering one aspect of the contemporary iconography of climate change, namely the images used in UK climate action campaigns in 2007 and 2008.

Although relatively short, the analytical timeframe allows for consideration of two contrasting varieties of campaign. One is public awareness or 'social marketing' campaigns, which seek change through an ethos of individual responsibility for remedial actions (Linder 2006). Campaigns such as 2007's Live Earth exemplify this 'bottom-up "social engineering"' approach to conquering climate change (Hulme 2008a, 12).

A second set of campaigns involves key members of the Stop Climate Chaos Coalition (SCCC) - an alliance of non-governmental organisations (NGOs) aiming to limit climate change impacts on the world's poorest through political action in the UK (see www. stopclimatechaos.org). In keeping with previous analysis of Greenpeace (which sits on the SCCC Board), I categorise this approach as one of 'bearing witness' to climate change, 'where the photographic framing of an action - how it will look visually - is a constitutive aspect of the action' (Doyle 2007, 131). The paper shows how sample campaigns aim to engage individuals as citizens as well as consumers.

Rather than exploring public reception of images, I focus here on the geopolitical (as well as scientific) visions of the world reproduced in selected exemplars of climate action campaigns. The first questions asked concern the meanings of the images themselves. What do notable images show and how, if at all, do they mirror the findings of climate change science? Is there a dominant iconography and if so what does it represent? To answer these, part one adopts the two-level semiotic analysis of meaning suggested by Roland Barthes's followers (see in particular Lidchi 1997 1999). The key themes are denotation (which refers to the most basic, descriptive level of meaning) and connotation (the more symbolic and cultural level).

In those terms, I argue that exemplary campaign images are collective denotations of the idea of global warming at the heart of scientific understandings of climate change. Globes are used routinely in climate change projections to denote possible futures (see the Met Office 2007), while pictures of humans and animals in contact with water denote early warning signs of long-terms trends and possible impacts. In scientific parlance, such conventional images as 
melting glaciers and flooded landscapes are visual 'fingerprints' and 'harbingers' of global warming and its local consequences (see www.climatehotmap.org).

In a wider cultural sense, the images analysed connote collective danger and individual vulnerability. The viewer may be told this explicitly. But even without the textual referents, connotations of danger and vulnerability can be deduced from visual signifiers of exposure to hazard.

Whereas the first part explores meaning at the 'site of the image itself' (Rose 2001, 30), the second part asks about the interplay of words and images. What are these campaigns trying to say, beyond the mundane (if sometimes contested) point that the world is getting warmer? Are they speaking with one voice or sending quite different messages, not only about climate change but also about their own geopolitical visions? Answering these questions demands not only visual analysis but also contextual exploration of broader cultural narratives.

The argument of the second part is that similar images are being used in dissimilar ways. The messages emitting from different campaigns display some clear tensions and contradictions in their geopolitical understandings of climate change. The key political questions in the climate change debate are not only about action (what should be done and by whom); they're also about justice (who suffers most and why) (Barnett 2007). I make sense of mixed political messages by situating them within two broader geopolitical narratives. The first is the 'whole-earth' discourse of global unity explored by Cosgrove (1994 2001). The second is the multifaceted discourse of development. Of particular relevance here are ties between the concepts of development and vulnerability.

Having highlighted competing visions of unity and diversity, I return to questions of cultural similarity and underlying consensus. The issue here is whether climate action campaigns reflect and perpetuate (however unwittingly) the values and principles of 'a distinctly Western construction of knowledge' (Bankoff 2001, 29). One key aspect is a so-called behavioural paradigm that emphasises voluntary behaviour change and individual responsibility. As already suggested, this emphasis is a defining element of the social engineering approach to climate action.

The other main aspect is 'the coloniser's model of the world' (Blaut 1993). Just as images of the globe have been linked to imperialist discourse (Cosgrove 2001, 263), so too has the concept of vulnerability been linked to colonial fears of the tropics (Bankoff 2001; Blaut 1993). In light of growing calls to move beyond vulnerability as cultural discourse, I review an Oxfam project entitled 'Sisters on the Planet'. I also weigh the virtues of political satire as employed in Christian Aid's 'Climate changed' campaign, i.e. the over-writing of icons of vulnerability with a deliberately contrasting tone of address.

In conclusion, I reiterate that the iconography of climate change used in contemporary climate action campaigns in the UK can be read as both a scientific early warning sign and a sign of the cultural times. Their proffered visions of a warming world are inherently political, and bound up not only with fingerprints and harbingers of climate change but also with geopolitical visions of the present and past.

\section{Dangerous worlds, vulnerable beings: the iconography of climate change}

Fingerprints and harbingers: denotations of global warming

Observational evidence from all continents and most oceans shows that many natural systems are being affected by regional climate changes, particularly temperature increases. (Intergovernmental Panel on Climate Change [IPCC] 2007a, 8)

Images of melting glaciers dominate the pictorial language of climate change, powerful symbols of a fragile earth at risk. (Doyle 2007, 129)

The campaign images under review fall roughly into the discernible (sometimes overlapping) categories presented in Table 1. Previous research in the UK and United States suggests treating this typology as conventional, with the possible exception of the category of people. The dominant iconography of climate change is arguably melting glaciers (Brönnimann 2002; Doyle 2007); the 'combination of polar bears and melting ice' (Garfield 2007); or 'non-human nature' more generally (Leiserowitz 2006, 52).

The classification scheme in Table 1 is followed by a brief denotative analysis. Before then, however, it should be noted that the term 'climate change' means different things to different organisations, the main protagonists being the IPCC and the United Nations' Framework Convention on Climate Change (UNFCCC). Whereas the former defines climate change as 'any change in climate over time, whether due to natural variability or as a result of human activity', the latter distinguishes between natural climate variability and anthropogenic (i.e. man-made) climate change (IPCC 2007a, 21). 
Table 1 Campaign images of climate change by category and type

\begin{tabular}{lll}
\hline Planet & Environment & Living beings \\
\hline Globes & $\begin{array}{l}\text { Flooded areas } \\
\text { Maps - choropleth and isarithmic* }\end{array}$ & $\begin{array}{c}\text { Animals - Polar bears, penguins } \\
\text { People - In floodwater, on parched land, } \\
\text { on glaciers }\end{array}$ \\
\hline
\end{tabular}

* Choropleth maps are those based on statistical data aggregated over previously defined regions. Isarithmic maps are those in which boundaries are defined by data patterns

The policy implications of those differences have been considered already (Pielke Jr 2005). The relevant point here is that, since atmospheric gases are invisible, it is impossible to see the greenhouse gas emissions that are one result of human activity. As observational devices, therefore, climate change images can only offer snapshots of the world at a particular moment in time. By implication, they cannot settle the definitional question or help to 'persuade the public that not all environmental problems can be seen' (Doyle 2007, 147).

The focus here is on 'observational evidence' of climate change, i.e. pictures of the current state of the world. As communication devices, visions of possible (often apocalyptic) futures meet the standard definition of a 'scenario' approach to climate change. Rather than a snapshot of the present, a scenario is 'a plausible and often simplified description of how the future may develop ... sometimes combined with a narrative storyline' (IPCC 2007b, 951; emphasis in the original). Analysis of the use of such scenarios in British and American media has been conducted already (Hulme 2004).

Specific images of the kind referred to in Table 1 are analysed in context throughout the remainder of the paper. The question for this section is whether those images mirror the findings of climate change science. My answer here is that they do - with a couple of notable exceptions.

First is the 'Apollo's eye' image of Earth from space analysed by Cosgrove (1994 2001) and recycled during Live Earth 2007. The NASA-photographed globe was a recurring backdrop to the various slogans and messages transmitted during 'Al Gore's sevencontinent, 24-hour concert series' (Burkeman 2007, 10). When first appearing behind London's Wembley stage, for example, the spherical Earth was overwritten with appeals to 'Save the Planet' and 'Answer the Call'. It reappeared in Washington behind the inspirational Gore, who identified the campaign goal as a 'sustainable, just and prosperous world for the 21st century'.
This demanded nothing less, Gore argued, than 'moral courage' to solve the climate crisis and 'save our planet' (BBC1 2007; see also Gore 2006).

Although two iconic NASA photographs named Earthrise (1968) and Spaceship Earth (1972) have done duty for environmentalism, their usage at Live Earth can only address one aspect of the 'global warming' concept. In research from the UK Hadley Centre, the warming of the globe is denoted with colour, i.e. with shades of red to denote possible rises in surface temperature. These coloured globes are not meant to represent our current world, however. They are projections of different future scenarios (see the Met Office 2007).

The second exception is the aforementioned 'photo exhibition of climate change and women', called 'Sisters on the Planet' (Oxfam 2008; Plate 1). The collection of photographs taken in countries of Oxfam operation is designed to accompany a film of the same name (see Activism team 2008). The series of portraits in the exhibition has the same dual purpose as the film (which also comes with an information booklet and call to action). Both aim to publicise first-hand experiences of global warming as well as 'the changes women are making to confront the problems they face' (Oxfam 2008, 1). The Sisters project is designed, furthermore, to support the message that climate change is a social justice and poverty issue. 'People not polar bears' is the accompanying slogan. ${ }^{1}$

Oxfam's Sisters are far removed from the images of suffering so often associated with humanitarian NGOs (see Manzo 2008). All are depicted in a positive light in the sense that they are no mere victims of climate change. These are working women and local activists. But while the Sisters can be read as positive icons of Oxfam's main slogan, which is 'helping people to help themselves', the photo exhibition could just as easily be subtitled 'women at work'. There is nothing in the images of women going about their daily business to provide observational evidence of climate change. Only the accompanying narratives that highlight growing pressures and risks convey the message that 


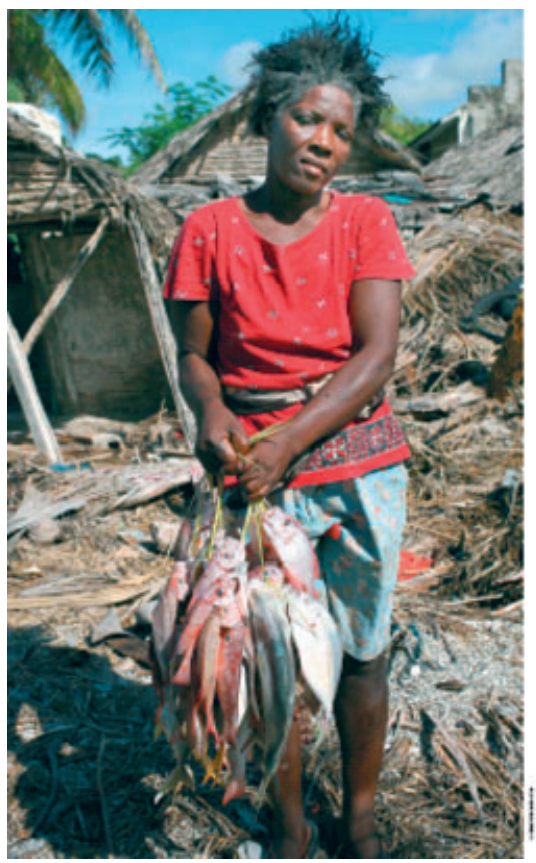

\section{Sisters on the Planet}

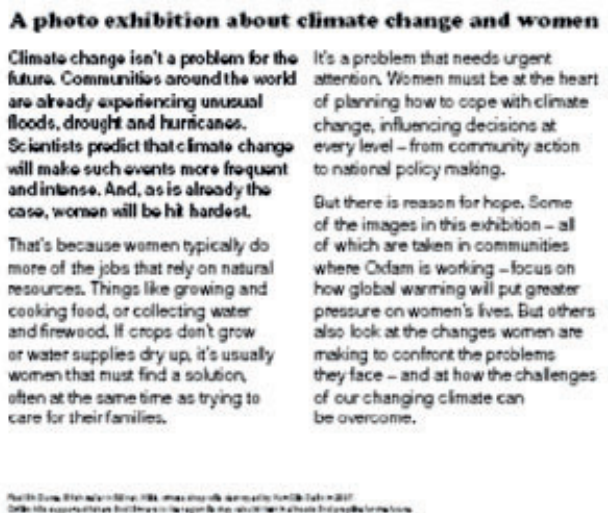

A phote exhibition about climate change and women

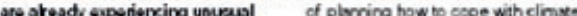
coods, drought and huricanes. Scientists prodict that e fimste change and fing toed, or collecting war of water supplies dry up it's usualy wornen that must find a solbon otten at the same time as trying to care bor theirfonilies.

Plate 1 Cover page of Sisters on the Planet (2008)

Source: Reproduced with kind permission of Oxfam

'communities around the world are already experiencing unusual floods, drought and hurricanes' (Oxfam 2008, 1).

'Extreme weather events' is the conventional umbrella term for unusual meteorological occurrences, i.e. events that are 'rare at a particular place and time of year' (IPCC 2007b, 945). Extreme weather must form a persistent pattern in order to qualify as anthropogenic (IPCC 2007b, 946). Nonetheless, climate change imagery often bears witness to such events, not only because they are capable of visualisation (unlike greenhouse gases), but also because they can live long in social memory (Brönnimann 2002, 89). A conventional signifier of extreme weather is water - specifically, visual indicators of abnormal patterns of rainfall.

The flood is a potent denotation of climate change because it is both a 'fingerprint' and 'harbinger' of global warming. In a document called 'Global Warming: Early Warning Signs' (the product of an international coalition of environmental organisations, including Sierra Club, Union of Concerned Scientists and World Wildlife Fund), fingerprints are defined as 'direct manifestations of a widespread and long-term trend toward warmer global temperatures'. They in- clude coastal floods and melting glaciers. Harbingers are 'events that foreshadow the types of impacts likely to become more frequent and widespread with continued warming'. Typical indicators are spreading disease, downpours and flooding, and droughts and fires (see www.climatehotmap.org).

It is to the cultural connotations of particular images that the paper now turns. The next section shows how climate action campaigns in the UK are up against a noted ambivalence toward global warming, wherein apocalyptic scenarios jostle with fantasies of Mediterranean summers in the UK (Boykoff 2008; Brönnimann 2002; Nicholson-Cole 2005). Far from any positive visions, current iconography mirrors the dominant tones of contemporary discourse, which are 'fear, misery and doom' (Boykoff 2008, 549) and 'danger and catastrophe' (Hulme 2008a, 6). At the epicentre of this discourse stands the figure of the vulnerable being.

\section{Hazards and vulnerability: connotations of global danger}

Climate change projections are scenario based and hence contain uncertainties. What constitutes danger will have to be a political decision. (O'Brien et al. 2006, 73) 
'Most people would prefer a hot climate', goes the marketing slogan for the Ford Fiesta Zetec Climate car (see Hickman 2008, 18). This is but one of 'a new generation of advert' that parodies discourses of danger for profit (Hickman 2008, 18; see also Linder 2006). These adverts come at a time when British ambivalence towards global warming has sparked a media debate about so-called green fatigue (see Society Guardian 2008). Academic research suggests, meanwhile, that public expressions of concern about climate rarely translate into behavioural change (Hulme 2008b; Leiserowitz 2006; Nicholson-Cole 2005).

In this context, campaigners have tended to either rely on the mass media for publicity (Nicholson-Cole 2005) or - as in the case of Oxfam's Sisters project - to work through affiliated institutions and political networks. ${ }^{2}$ Visual images are deployed either way in support of discernible methods of consciousnessraising. One approach is to shore up the idea of a scientific consensus on climate change. A notable example is the documentary An Inconvenient Truth, which intersperses iconic NASA photographs with statistical maps, family snapshots, and images of 'harbingers' and 'fingerprints' (Gore 2006).

Another example is the British coverage of Live Earth, which relied on the BBC's environment correspondent to disseminate scientific opinion. Global warming is man-made; carbon emissions must be urgently reduced; the rate of change is startling. Supplementing these core messages was footage of conventional climate change images, such as the Antarctic and a solitary penguin (BBC1 2007).

A complementary method of consciousness-raising is to reinforce conceptions of danger. As the quote above suggests, this approach is inherently political as it exceeds the limits of natural science models (see also Oppenheimer 2005; Pielke Jr 2005). A case in point is the scientific debates about thresholds of danger.

A threshold is a point (such as a temperature increase of $2^{\circ} \mathrm{C}$ ) 'beyond which many believe substantial damage would occur' (Schneider 2001, 3). ${ }^{3}$ Definitions of danger are common in climate science even if people's subjective perceptions are 'underresearched' (Dessai et al. 2004, 15). Some scientists measure danger through thresholds in physical vulnerability (such as loss of coral reef), while others do so via thresholds in social vulnerability (e.g. greater numbers at risk from such denotations of global warming as water shortages, disease, hunger and coastal flooding). There are thus varying definitions of danger, even if a common assumption is that danger can be objectively measured. Furthermore, there is controversy over the likelihood of some thresholds, with scientists being asked to 'justify the threshold they choose for predicting "dangerous" climate change' (Schneider 2001, 3).

Even if science cannot provide a universal definition of dangerous climate change, the standard measurements show an inseparable link between danger and vulnerability. It is this link that has been woven into campaigns that (like 'Sisters on the Planet') send the message that dangerous climate change is already here.

A commonly used vehicle for that message is the iconography of disaster. An exemplary illustration is Christian Aid's 'Climate changed' advertisements the public awareness wing of a two-year strategic campaign initiated in 2006. While lobbying (with other SCCC members) for the emissions reduction targets ${ }^{4}$ now contained in the UK Climate Change Act (2008), Christian Aid redeployed stock images ${ }^{5}$ of 'suffering with dignity' (such as those in the Plates below) ${ }^{6}$ to advertise 'the already seen effects of climate change' (Doyle 2007, 129; emphasis in the original). As with Oxfam's Sisters, the overall aim is to 'move the UK public on from the notion that polar bears are the face of climate change ${ }^{17}$ while promoting the message that climate change is 'a justice issue' and therefore political. ${ }^{8,9}$

Other campaign images of flood-related loss and displacement are more deliberately global in scope. Comparative photography features, for example, in a Friends of the Earth 'Big Ask' campaign pamphlet, which juxtaposes a British man and a woman from an unspecified 'tropical region' (Friends of the Earth 2008). Equally illustrative is 'Drowned Worlds', a photo essay of flood victims in England and India commissioned by Action Aid (Mendel 2007).

Vulnerability is often conceived as 'a "threat" or "exposure" to a hazard' (Manyena 2006, 441). The people in the aforementioned campaigns are therefore fairly conventional icons of vulnerability. Another notable example is the photograph of 600 naked bodies on a Swiss glacier commissioned by Greenpeace (see The Observer 2007, 30). Even if the iconic glacier is obviously melting, the presence of bare humans connotes an immediate sense of exposure to hazard (i.e. the prospect of freezing to death). That, indeed, is the stated aim of the photographer, who wants viewers 'to feel the vulnerability of their existence and how it relates closely to the sensitivity of the world's glaciers' (Spencer Tunick, quoted in The Observer 2007, 30). 
In summary, climate action campaigns routinely represent global warming as a dangerous hazard. There are key differences, however, in terms of how vulnerability is embodied in space. Whereas some campaigns feature particular people, others embrace all living things. The next part situates those differences in broader context before returning to the issue of cultural similarity and underlying consensus.

\section{Mixed messages and geographical visions: discourses of unity and diversity}

The 'whole-earth' discourse: global danger, fear and risk

A 'whole-earth' discourse stresses the globe's organic unity ... It emphasises the fragility and vulnerability of a corporeal earth and responsibility for its care. It can generate apocalyptic anxiety about the end of life on this planet or warm sentiments of association, community, and attachment. (Cosgrove 2001, 262-3)

Climate change is seemingly 'a global problem that will require a global solution' (King 2005, 783). It is a problem, furthermore, of 'the global commons of the atmosphere', whose impacts cannot be restricted to contributing countries (Elliott 1998, 53).

Relevant policies arguably require a global vision, of the sort captured to date in two modes of iconography already mentioned. One is the 'Apollo's eye' image of the spherical Earth; the other is the comparative photography exemplified by 'Drowned Worlds'. In exploring the discursive framing of these images, the remainder of this section emphasises the correspondence between narratives of unity and connotations of vulnerability.

As suggested in the quote above, the term wholeearth refers to one of the global ideologies expressed in 'Apollo's eye' images of the planet (the other, 'oneworld' discourse is reviewed later). As frequently noted (e.g. Ward and Dubos 1972; Ingold 1993; Macnaghten 2003; Gore 2006), this Apollonian vision of an interconnected, fragile Earth is routinely signified by NASA's iconic photographs.

Nonetheless, the use of the sphere in climate action campaigns is not without apparent limitations. The unscripted globe is no more a signifier of fragility and vulnerability than it is of global warming. Those connotations must therefore be spelled out - as they are, for example, in An Inconvenient Truth (Gore 2006). With the NASA photographs as a backdrop, the viewer is informed that the Earth is vulnerable because its atmosphere is so thin. The vulnerability of humankind, by implication, is a function of the vulnerability of an ozone layer that cannot be seen.

That level of abstraction helps explain why - in addition to 'apocalyptic anxiety' - images of the globe can reinforce feelings of alienation and detachment (Ingold 1993). In one UK study, for example, focus groups that associated the sphere with familiar global threats (such as warming and ozone depletion) also 'tended to perceive such threats as a problem "out there", detached from everyday life, making it easy for them to turn off' (Macnaghten 2003, 72).

'Drowned Worlds' makes the option of disengagement more difficult. As one commentator noted, the essay's visual power stems from the cultural potency of flood stories and myths (like the biblical Noah's Ark) in combination with the humanity of subjects who 'gaze into our eyes as if we ought to know them'. Through his juxtaposition of shared experiences in dissimilar circumstances, 'Mendel shows two different worlds united, not separated, by the floods: we are all in this together' (Gee 2007, 2).

That message of shared risk and collective threat serves the argument that climate change must hit home in order to move people to action (Dessai et al. 2004; Leiserowitz 2006; Nicholson-Cole 2005). But as much as greenhouse gas emissions produce global effects, suggestions of universal impact have not gone unchallenged. As the following section demonstrates, the 'whole-earth' discourse of global unity is but one way to frame images of vulnerability in climate action campaigns.

The discourse of development: global inequality, justice and rights

Resource-dependent and low-income societies are ... more vulnerable to climate change than are wealthy people and societies. (Barnett 2007, 1363)

Developing countries are expected to be disproportionately impacted by ... increased climate variability ... Bank support to clients focuses on three key areas: mitigation of greenhouse gas emissions; reducing vulnerability and adapting to climate change; capacity building. (World Bank 2008)

Vulnerability can be measured in different ways (as mentioned already) and so too can development. Common indicators are of economic development such as Gross Domestic Product (GDP) - as well as 'millennium development' agenda items like water shortage, malaria, hunger and coastal flooding (see United Nations 2008). These varying indicators 
demonstrate that 'development' has no singular meaning, even after 'fifty years of development thinking' (Schuurman 2000, 8) and the rise of a 'postdevelopment' paradigm (Pieterse 2000). This paper cannot explore debates about the concept of development itself. The aim here is to show how discourses of development (however understood) and 'the recently emerged cultural narrative of vulnerability' (Furedi 2007, 487) have been married in climate action campaigns.

The above quotes assume that particular places are necessarily zones of greatest vulnerability to climate change, and that its impacts are spatially varied even if atmospheric emissions are transnational (Barnett 2007, 1361). But while many writers on disaster agree that 'the world's poorer nations are disproportionately affected' by climate-related hazards (O'Brien et al. 2006, 64), they argue that poverty and vulnerability are not the same thing. Vulnerability is not a 'natural state' anywhere (Furedi 2007, 487). It may be a function of factors other than income level, such as social marginality (O'Brien et al. 2006, 64) or rapid urbanisation (Schipper and Pelling 2006, 25). A simple poverty = vulnerability equation furthermore 'fails to explain how people at the same income level do not suffer equally from disaster' (Bankoff 2001, 25).

Such critiques help account for the latest addition to a 'vulnerability paradigm' once focused at the individual or community level, i.e. the concept of 'vulnerable groups' (Furedi 2007, 487-8). Although the entire global poor may still be labelled as such, the epithet is often applied to sub-populations such as the elderly (see O'Brien et al. 2006, 68) and women and children (Furedi 2007, 488).

Images of human vulnerability in NGOs' climate action campaigns reflect a linguistic turn among NGOs themselves. The concept of 'vulnerable groups' exists within a broader reframing of both long-term development and emergency relief as 'rights-based'. Governmental organisations, such as the UK's Department for International Development $(2000,6)$, entwine rights and vulnerability under the umbrella of pro-poor development. NGOs, however, typically express their commitments to the vulnerable in terms of justice and solidarity, including the amended principle of innocence-based solidarity that foregrounds women, children and the elderly in particular (Manzo 2008, 647).

Justice and solidarity are advocacy terms that signal a departure from traditionally apolitical humanitarian principles of neutrality and impartiality (Manzo 2008; Slim 1997). The aforementioned 'Sisters' and 'Climate changed' campaigns are both political in the sense of demanding action from politicians and citizens alike. The latter are asked to pressure the former to keep up the fight against climate change.

However, as much as campaign images connote innocence-based solidarity, accompanying texts speak of 'the world's poorest people' (see Plate 3) and 'vulnerable developing countries' (Oxfam 2008, 12). This suggests a continued debt to the idea of zones of vulnerability - the implications of which are considered below.

\section{The coloniser's model of the world? Vulnerability and Western liberalism}

The discourse of vulnerability, no less and no more than that of tropicality or development, belongs to a knowledge system formed from within a dominant Western liberal consciousness and so inevitably reflects the values and principles of that culture. (Bankoff 2001, 29)

It is always wise to keep in mind that an emphasis on global problems, and particularly those that seem to loom as future catastrophe, tends to arise primarily from within those societies that have harboured imperial dreams. (Walker 1988, 194)

This section asks whether climate action campaigns reflect distinctly Western ideologies and worldviews. I suggest they do to some extent, before weighing the virtues of alternative discourses and modes of address.

The first consideration is the social engineering approach to climate change action. An exemplary illustration of this was Live Earth, which peppered the musical interludes with several short films promoting personal responsibility to diminish 'carbon footprints' (i.e. carbon emissions per capita). Practical strategies included loft insulation, recycling and boiling less water in kettles (BBC1 2007).

Mass social engineering approaches of that sort may be of limited value in defusing climate catastrophe (Hulme 2008a, 12). The point here is that such approaches are indicative of a 'behavioural paradigm' apparent in many other policy arenas. Interventions against HIV/AIDS in Africa, for example, have 'stuck faithfully to the liberal script' of voluntary behaviour change and individual responsibility (de Waal 2006, 48; quoted in Campbell 2008, 22).

That script on HIV/AIDS is arguably depoliticising in the way it abstracts the experiences of individuals from the institutional contexts that govern health care provision (Watney 1990; cited in Campbell 2008, 32). That same point can be made about climate change. 


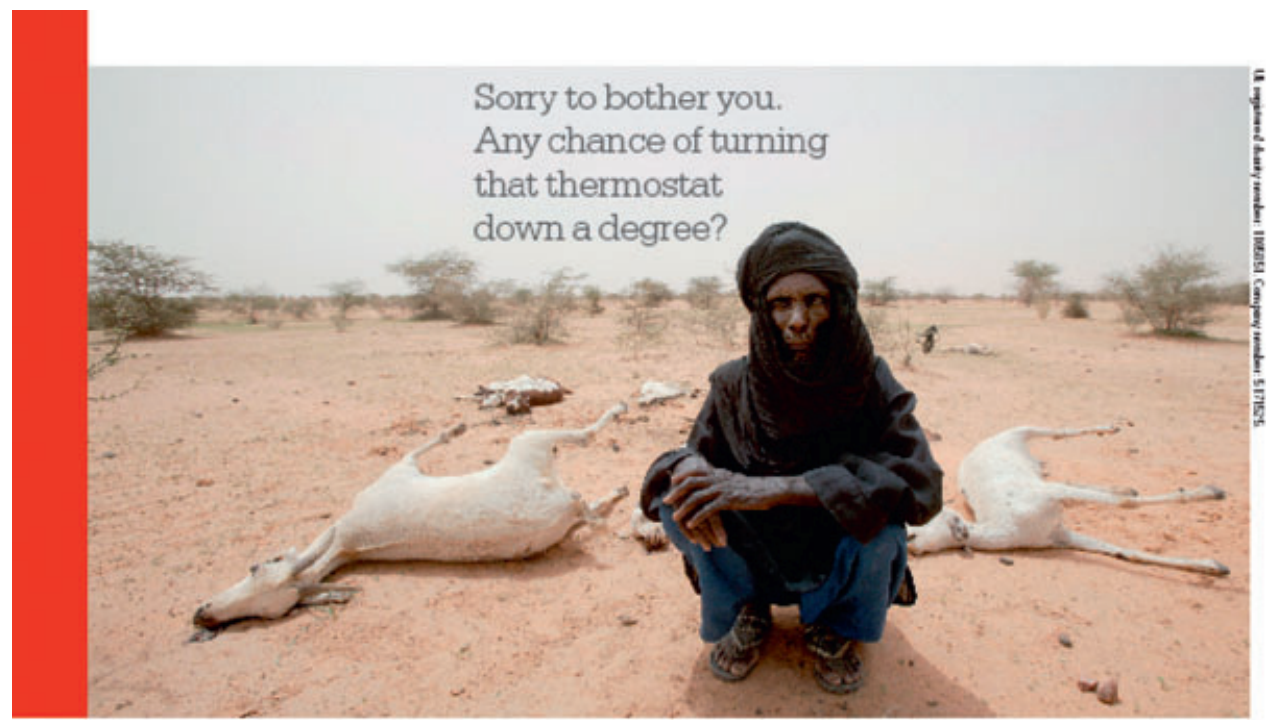

Climate change isn't some threat to the future. It's today's reality. Environmental disasters, such as droughts in Niger, are wrecking people's lives with more and mote frequency. And it's gotng to get worse. Want to do something about it? Good, we need people like you. Viatt our webstte to see how you and your workplace can change the world for the better. Climate changed. Let's get to work. Www.climatechanged.org

Plate 2 'Goat man' - Christian Aid 'Climate changed' advertisement (2007)

Source: Original photograph from Niger by Crispin Hughes for Panos Pictures (www.panos.co.uk). Reproduction of advertisement with kind permission of Christian Aid

Individuals are not the only relevant culprits; questions must also be asked about the contributing roles played by public institutions and policies.

Campaigns aimed at 'government's regulatory role in mitigation' (Linder 2006, 103) address one side of the policy coin, namely strategic response. But the other, equally important side is the relationship between development policies and exposure to hazard. The so-called neo-liberal paradigm of development, with its emphasis on market forces and minimalist states, remains dominant despite the rise of alternative models of people-centred development and rights-based development (Manzo 2000 2003). By promoting policies that assist 'footloose capitalism' while weakening states, neo-liberalism only exacerbates poverty and increases the vulnerability of the poor to disaster (Schipper and Pelling 2006, 22-3).

Critique of neo-liberalism is inherent in $\mathrm{NGOs}^{\prime}$ embrace of rights-based development as well as in social justice campaigns around issues of aid, trade and debt. Climate action campaigns that highlight social justice and poverty issues are thus but one dimension of wider agendas for change. But I've argued before that campaign images of children (which are designed to connote innocence-based solidarity) can unwittingly reproduce colonial visions of a superior global north and an inferior south (Manzo 2008). The question that raises here is whether NGOs can highlight global inequalities without recycling Western visions of a 'temperate world' that exercises 'dominion over tropical realms' (Livingstone 2002, 174). The issue is particularly acute given that extreme weather (and disease) was a defining feature of 'the tropical nastiness doctrine' (Blaut 1993, 70).

One possibility is to de-emphasise difference and highlight connectedness instead. Plate 2's so-called goat $\operatorname{man}^{10}$ arguably does both - and in a way that avoids the pitfalls of a 'one world' discourse of unity and equality (around which Apollo space images have also been framed). Critics argue that 'images of connection' are 'thoroughly misleading' when they only emphasise 'universalisation and centralisation' (Walker 1988, 104). Concentration on global networks may also yield 'an implicitly imperial spatiality, connecting the ends of the earth to privileged hubs and centres of control' (Cosgrove 2001, 263).

Another alternative is to de-emphasise vulnerability. This may be done by reimagining exposure to hazard 


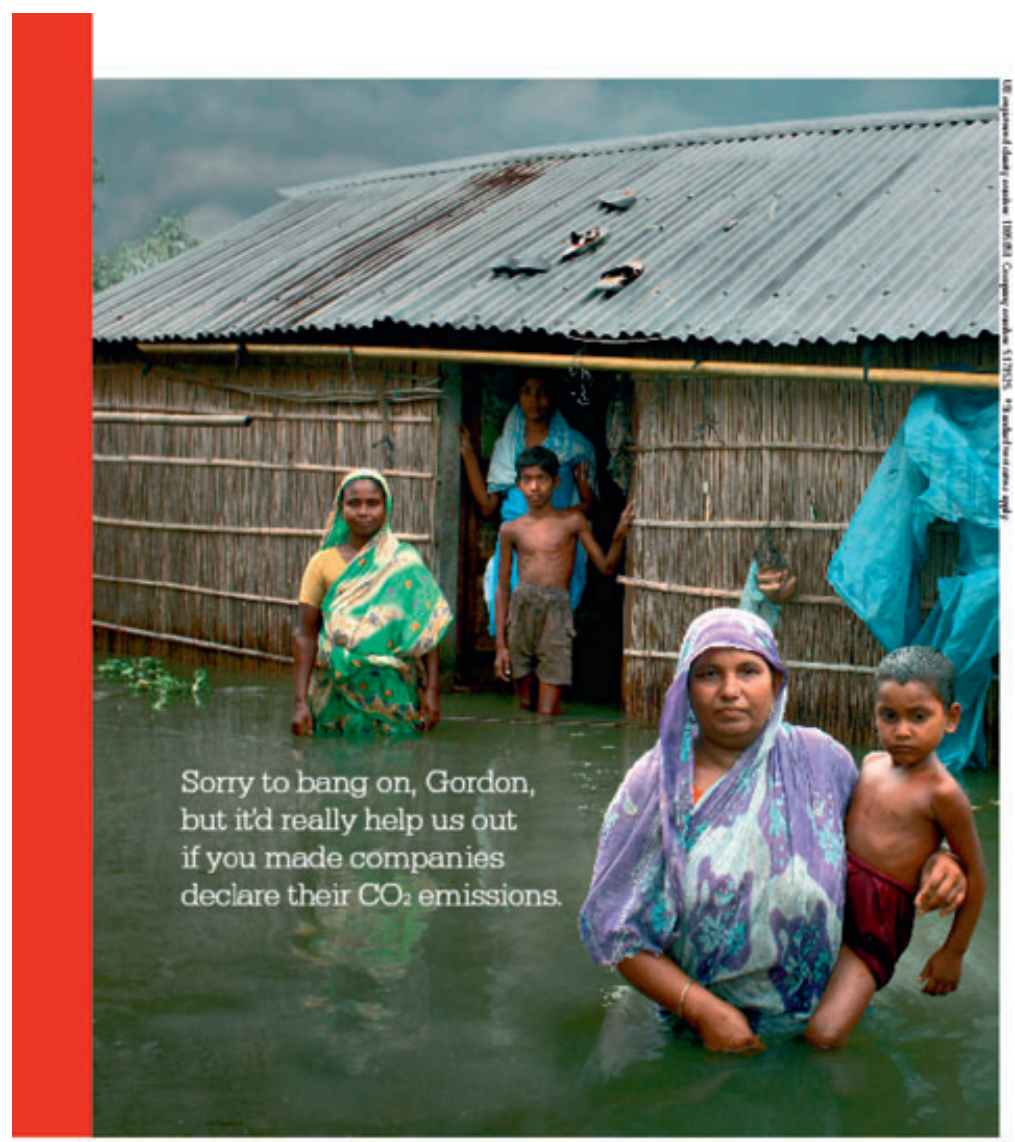

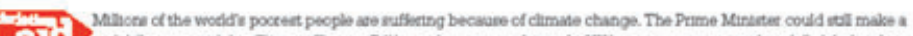

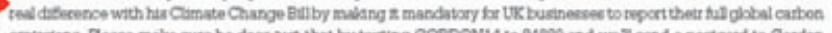

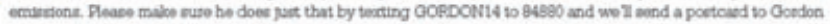
Btown (and yout local MP) on your behalf Ot go to www chnetsanud org ule dimateball to rend an email youtself Cimate changed. terb cut the carbon.

Plate 3 Christian Aid 'Climate changed' advertisement (2008)

Source: Original photograph from Bangladesh by Akash for Panos Pictures (www.panos.co.uk). Reproduction of advertisement with kind permission of Christian Aid

as a consequence of two measures, i.e. cultural adaptability and resilience, on the one hand, and social vulnerability on the other (Bankoff 2001; Furedi 2007; Manyena 2006; O'Brien et al. 2006; Schipper and Pelling 2006). Another possibility is the one favoured by the World Bank (2008), i.e. the transport of the concept of 'capacity building' from the NGO model of people-centred development (see Eade 1997) into policies of vulnerability reduction and climate change adaptation.

A third approach is to raise political questions about what Boykoff calls 'differentiated vulnerability and abilities to cope with climate change' $(2008,559)$. As well as advertising the vulnerability of particular people (such as the women in Oxfam's Sisters project), this approach draws attention to the 'unequal structural, political or institutional conditions' that render some people more vulnerable than others (Boykoff 2008, 559).

Christian Aid's 'Climate changed' advertisements are designed to do precisely that. Plate 2 's call to viewers to turn down their thermostats places the onus for change on individuals and is thus further indication of a behavioural paradigm at work. But it also (like Plate 3) implies a speaking subject instead of the silenced 'subalterns' at the heart of dominant 
representations of the majority world (Spivak 1988; see also Kapoor 2008). Addresses to the viewer (who may be a politician, as in Plate 3 ) are delivered in an ironic tone deliberately at odds with visual connotations of danger and vulnerability. Designed to circumvent guilt and empower the viewer to act, ${ }^{11}$ the deployment of political satire is not an especially novel way to gain public attention. It features as well in the climate change discourse of the UK tabloid press (Boykoff 2008). What sets the Christian Aid advertisements apart is their attention to the very issues left unaddressed by the tabloids, i.e. asymmetrical power relations and global injustice.

\section{Conclusion}

This paper showed that danger and vulnerability are the dominant signifiers of global warming in two contrasting varieties of UK climate action campaign. The 'social engineering' or 'social marketing' approach was exemplified here by Live Earth - the global extravaganza inspired by $\mathrm{Al}$ Gore and his documentary An Inconvenient Truth. The one-day event was designed (in the words of its executive producer) to focus ' 2 billion pairs of eyeballs' on associated climate change images and messages (Kevin Wall, quoted in Smith 2007, 22).

Live Earth therefore operated at a larger scale than the campaigns undertaken in the study timeframe by selected NGOs. I categorised their campaigns as illustrations of a 'bearing witness' approach to climate change, which interweaves political calls to action with images of 'the already seen effects of climate change' (Doyle 2007, 129; emphasis in the original). In drawing attention to such extreme weather events as floods, members of the SCCC have self-consciously placed people at the centre of what climate science refers to as 'fingerprints' and 'harbingers' of global warming. Iconographic images of disaster (such as Plates 2 and 3) thus challenge and endorse what previous research suggests is the dominant iconography of climate change, i.e. melting ice, polar bears and nonhuman nature more generally.

Having highlighted the competing narratives and geopolitical visions emitting from different campaigns, the paper identified the shared Western underpinnings of varying discourses of unity and diversity. This prompted the question of whether it's possible to highlight uneven development without re-energising either neo-liberal development models or colonial visions of the world. Reviewed alternatives all suggest moves away from the premise that the entire global south is a zone of vulnerability in need of Western intervention and rescue. Vulnerability, in other words, must be contextualised and politicised as well as connoted through images of suffering, disaster and hazard.

The broader lesson of the paper is that the iconography of climate change is itself inherently political for two reasons. Firstly, climate science can provide denotations of global warming but it cannot objectively determine what constitutes danger. Not only are there scientific debates about thresholds of danger; connotations of danger are also subjectively varied and culturally driven. Secondly, the climate action campaigns of NGOs such as Oxfam and Christian Aid are only partly in the difficult business of trying to prove 'that climate change is real through visual means' (Doyle $2007,147)$. They also raise political questions about action and justice.

Further research into climate action campaigns is thus the stuff of geopolitics, development geography and cultural geography as well as of environmental science and activism.

\section{Acknowledgements}

Many thanks for their time, insights and use of images to Kim Tan at Oxfam and Eliot Whittington, Eleanor Ramsey and Christiane Diehl at Christian Aid. My thanks also go to Adrian Evans at Panos Pictures and to two anonymous journal reviewers for helpful comments on an earlier draft.

\section{Notes}

1 Kim Tan, Oxfam campaigns officer, interview with the author 23 September 2008.

2 Launched in London in 2008, Sisters has been shown thus far to the Women's Institute and other women's groups as well as to branches of the trade union movement. The photographs have also been exhibited in the gallery of the Houses of Parliament. Interview with Kim Tan, September 2008.

3 The SCCC is among such believers, demanding 'political action in the UK to prevent global warming rising beyond the two degrees Centigrade danger threshold' (www. stopclimatechaos.org/08/oct/we-are).

4 For a useful overview see Parliamentary Office of Science and Technology (2008).

5 By 'stock images' I mean those sourced from image banks as opposed to bespoke photographs taken by Christian Aid. See Plates 2 and 3 for the original sources of campaign photographs.

6 Christiane Diehl, Christian Aid advertising and marketing officer, interview with the author 31 October 2008.

7 Eleanor Ramsey, Christian Aid campaigns officer, correspondence with the author 1 December 2008. 
8 Eliot Whittington, Christian Aid campaigns officer, correspondence with the author 23 October 2008.

9 These and other advertisements appeared in newspapers at routine intervals during the two-year campaign. See for example The Guardian 23 March 2007, 28 and 26 September 2007, 3; see also The Observer 16 March 2008, 3.

10 According to Christiane Diehl of Christian Aid, the 'goat man' label was applied by the campaign team (i.e. not by the photographer).

11 The use of humour, and the contrast between severity of image and tone of address, was a deliberate strategy of the advertising campaign. My thanks go to Christiane Diehl of Christian Aid for these insights.

\section{References}

Activism team 2008 Everybody's talking about Sisters Activist news: the monthly newsletter for Oxfam activists July (http:// www.oxfam.org.uk) Accessed 15 July 2008

Bankoff G 2001 Rendering the world unsafe: 'vulnerability' as western discourse Disasters 25 19-35

Barnett J 2007 The Geopolitics of climate change Geography Compass 1 1361-75

BBC1 2007 Live Earth 7 July

Blaut J M 1993 The coloniser's model of the world: geographical diffusionism and Eurocentric history The Guilford Press, London

Boykoff M T 2008 The cultural politics of climate change discourse in UK tabloids Political Geography 27 54969

Brönnimann S 2002 Picturing climate change Climate Research 22 87-95

Burkeman O 2007 Al Gore rocks the world, but will he save the planet? The Guardian 9 July 10

Campbell D 2008 The visual economy of HIV/AIDS (http://www.visual-hivaids.org/overview.html) Accessed 30 January 2009

Cosgrove D 1994 Contested global visions: one-world, wholeearth, and the Apollo space photographs Annals of the Association of American Geographers 84 270-94

Cosgrove D 2001 Apollo's eye: a cartographic genealogy of the earth in the western imagination The Johns Hopkins University Press, London

Department for International Development 2000 Making globalisation work for the world's poor December (http:// www.dfid.gov.uk/pubs/files/wp2000intro.pdf) Accessed 24 July 2008

Dessai S, Adger W N, Hulme M, Turnpenny J, Kohler J and Warren R 2004 Defining and experiencing dangerous climate change Climatic Change 64 11-25

De Waal A 2006 AIDS and power: why there is no political crisis - yet Zed Books, London

Doyle J 2007 Picturing the clima(c)tic: Greenpeace and the representational politics of climate change communication Science as Culture 16 129-50
Eade D 1997 Capacity-building: an approach to peoplecentred development Oxfam UK and Ireland, Oxford

Elliott L 1998 The global politics of the environment Macmillan, London

Friends of the Earth 2008 The big heat (pamphlet) (http://www. foe.co.uk/campaigns/climate/news/big_ask.html) Accessed 17 July 2008

Furedi F 2007 The changing meaning of disaster Area 39 482-9

Garfield S 2007 Living on thin ice The Observer Magazine 4 March 32-7

Gee M 2007 Drowned worlds (http://www.guardian.co.uk/ environment/2007/dec/20/flooding.naturaldisasters)

Accessed 18 July 2008

Gore A 2006 An inconvenient truth: a global warning (DVD)

Hickman L 2008 Driven by mischief The Guardian (section G2) 24 January 18-19

Hulme M 2004 Pictures, scenarios or probabilities: how should we portray dangerous climate change? Prepared for the conference on 'Perspectives on Dangerous Climate Change', University of East Anglia, 28-29 June

Hulme M 2008a The conquering of climate: discourses of fear and their dissolution The Geographical Journal 174, 1 (March) 5-16

Hulme M 2008b Geographical work at the boundaries of climate change Transactions of the Institute of British Geographers 33 5-11

Ingold T 1993 Globes and spheres: the topology of environmentalism in Milton K ed Environmentalism: the View from anthropology Routledge, London 31-42

Intergovernmental Panel on Climate Change (IPCC) 2007a Summary for policymakers in Parry M L, Canziani O F, Palutikof J P, Van der Linden P J and Hanson C E eds Climate change 2007: impacts, adaptation and vulnerability. Contribution of working group II to the fourth assessment report of the intergovernmental panel on climate change Cambridge University Press, Cambridge UK 7-22

IPCC 2007b Glossary of terms used in the IPCC fourth assessment report (http://www.ipcc.ch/glossary/index.htm) Accessed 14 July 2008

Jasanoff S 2007 Modelling the world: vision and representation in the politics of climate change Public lecture series 'models of the future' Institute of Advanced Study, University of Durham, 14 January 2007

Kapoor I 2008 The postcolonial politics of development Routledge, London

King D 2005 Climate change: the science and the policy Journal of Applied Ecology 42 779-83

Leiserowitz A 2006 Climatic change risk perception and policy preferences: the role of affect, imagery, and values Climatic Change 77 45-72

Lidchi H 1997 The poetics and the politics of exhibiting other cultures in Hall S ed Representation: cultural representations and signifying practices Sage, London 151-208

Lidchi H 1999 Finding the right image: British development NGOs and the regulation of imagery in Skelton $\mathbf{T}$ and Allen T eds Culture and global change Routledge, London 87-101 
Linder S H 2006 Cashing-in on risk claims: on the for-profit inversion of signifiers for 'global warming' Social Semiotics 16 103-32

Livingstone D N 2002 Race, space and moral climatology: notes toward a genealogy Journal of Historical Geography 28 159-80

Macnaghten P 2003 Embodying the environment in everyday life practices Sociological Review 51 63-84

Manyena S B 2006 The concept of resilience revisited Disasters 30 433-50

Manzo K 2000 Nongovernmental organisations and models of development in India The Journal of Environment and Development 9 284-313

Manzo K 2003 Africa in the rise of rights-based development Geoforum 34 437-56

Manzo K 2008 Imaging humanitarianism: NGO identity and the iconography of childhood Antipode 40 632-57

Mendel G 2007 Drowned worlds (http://www.guardian.co.uk/ environment/gallery/2007/dec/20/1 ?picture=331859103)

Accessed 18 July 2008

Met Office 2007 Climate change projections (http://www. metoffice.gov.uk/research/hadleycentre/models/modeldata. html) Accessed 14 August 2007

Nicholson-Cole S A 2005 Representing climate change futures: a critique on the use of images for visual communication Computers, Environment and Urban Systems 29 255-73

O'Brien G, O'Keefe P, Rose J and Wisner B 2006 Climate change and disaster management Disasters 30 64-80

Observer 2007 Say freeze: why 600 people stripped and posed on a Swiss glacier The Observer 19 August 30

Oppenheimer M 2005 Defining dangerous anthropogenic interference: the role of science, the limits of science Risk Analysis 25 1399-407

Oxfam 2008 Sisters on the planet: a photo exhibition about climate change and women (courtesy of Oxfam)

Parliamentary Office of Science and Technology 2008 The transition to a low carbon economy Postnote 318 (http:// www.parliament.uk/parliamentary_offices/post/pubs2008. cfm) Accessed 16 January 2009

Pielke Jr R A 2005 Misdefining 'climate change': consequences for science and action Environmental Science and Policy 8 548-61

Pieterse J N 2000 After post-development Third World Quarterly 21 175-91

Rose G 2001 Visual methodologies: an introduction to the interpretation of visual materials Sage, London

Schipper L and Pelling M 2006 Disaster risk, climate change and international development: scope for, and challenges to, integration Disasters 30 19-38

Schneider S H 2001 What is 'dangerous' climate change? Nature 411 17-19

Schuurman F J 2000 Paradigms lost, paradigms regained? Development studies in the twenty-first century Third World Quarterly 21 7-20

Slim H 1997 Relief agencies and moral standing in war: principles of humanity, neutrality, impartiality and solidarity Development in Practice 7 342-52

Smith D 2007 Gore show is set to be biggest on earth The Observer 1 July 22

Society Guardian 2008 Climate change: the fight against 'green' fatigue The Guardian 16 July 1-6

Spivak G C 1988 Can the subaltern speak? in Nelson C and Grossberg L eds Marxism and interpretation of culture University of Illinois Press, Chicago IL 271-316

United Nations 2008 UN millennium development goals (http://www.un.org/millenniumgoals) Accessed 23 July 2008

Walker R B J 1988 One world, many worlds: struggles for a just world peace Zed Books, London

Ward B and Dubos R 1972 Only one earth: the care and maintenance of a small planet Pelican, London

Watney S 1990 Missionary positions: AIDS, 'Africa' and 'Race' in Ferguson R, Gever M, Minh-ha $\mathbf{T}$ and West $\mathbf{C}$ eds Out there: marginalisation and contemporary cultures MIT Press, Cambridge MA 89-103

World Bank 2008 Climate change (http://go.worldbank.org/ 75DLOCZFG0) Accessed 11 July 2008 